\title{
Chemotherapy for Well-Differentiated Pancreatic Neuroendocrine Tumours with a Ki-67 Index $\geq 10 \%$ : Is There a More Effective Antitumour Regimen? A Retrospective Multicentre Study of the French Group of Endocrine Tumours (GTE)
}

\author{
Guillaume Roquin $^{\mathrm{a}}$ Eric Baudin ${ }^{\mathrm{b}}$ Catherine Lombard-Bohas ${ }^{c}$ Guillaume Cadiot ${ }^{\mathrm{d}}$ \\ Sophie Dominguez ${ }^{\mathrm{e}}$ Rosine Guimbaud ${ }^{f}$ Patricia Niccolig Jean-Louis Legoux ${ }^{\mathrm{h}}$ \\ Emmanuel Mitry ${ }^{i}$ Vincent Rohmer ${ }^{j}$ Philippe Ruszniewski ${ }^{k}$ Thomas Walter $^{c}$ \\ Michel Ducreux' Anne Couvelard ${ }^{m}$ Jean-Yves Scoazec ${ }^{n} \quad$ Aline Ramond-Roquin $^{\circ}$ \\ François-Xavier Caroli-Bosc ${ }^{a}$ Olivia Hentick

\begin{abstract}
${ }^{a}$ Department of Hepatogastroenterology and Digestive Oncology, CHU Angers, Angers University, LUNAM University, Angers, ${ }^{b}$ Department of Nuclear Medicine and Endocrine Oncology, Institut Gustave Roussy, Villejuif, 'Department of Medical Oncology, Edouard-Herriot University Hospital, Lyon, d Department of Hepatogastroenterology and Digestive Oncology, Robert-Debré University Hospital, Reims, e Department of Oncohematology, Saint Vincent de Paul Hospital, Lille, ${ }^{\mathrm{f}}$ Department of Digestive Medical Oncology, Toulouse University Hospital, Toulouse, ${ }^{9}$ Department of Medical Oncology, Institut Paoli-Calmette, Marseille, h Department of Gastroenterology, Orléans Hospital, Orléans, 'Department of Medical Oncology, Curie Institute, Paris-St Cloud, 'Department of Endocrinology, CHU Angers, Angers University, LUNAM University, Angers, ${ }^{k}$ Department of Gastroenterology and Pancreatology, Beaujon University Hospital, Clichy, 'Department of Gastrointestinal Oncology, Institut Gustave Roussy, Villejuif, m Department of Pathology, BeaujonBichat University Hospitals, Clichy/Paris, " Department of Pathology, Edouard-Herriot University Hospital, Lyon, and ${ }^{\circ}$ Department of General Practice, Faculty of Medicine, Angers University, LUNAM University, Angers, France
\end{abstract}

\section{Keywords}

Chemotherapy · Differentiation · Gastroenteropancreatic endocrine tumours · Proliferation · Ki-67 index

\begin{abstract}
Background: The best chemotherapy regimen for welldifferentiated pancreatic neuroendocrine tumours (pNETs) with a Ki-67 index $\geq 10 \%$ is still debated. We evaluated the antitumour efficacy of various first-line chemotherapy regimens (streptozocin based, platinum based, or dacarbazine/ temozolomide based) in this situation. Methods: In this ret-
\end{abstract}

\section{KARGER}

(C) 2017 S. Karger AG, Basel

E-Mail karger@karger.com

www.karger.com/nen rospective multicentre study of the French Group of Endocrine Tumours (GTE), we recruited consecutive patients with advanced well-differentiated pNETs and a Ki-67 index $\geq 10 \%$ receiving chemotherapy between 2000 and 2012. The primary endpoint was progression-free survival (PFS) according to RECIST. Results: Seventy-four patients (42 men, median age 55.5 years) were enrolled from 10 centres. Fifty-one patients (69\%) had grade 2 NET and 61 (82\%) were stage IV. Median overall survival was 36.3 months. Forty-four patients (59\%) received streptozocin-based, 18 (24\%) platinumbased, and 12 (16\%) dacarbazine/temozolomide-based chemotherapy regimens. These 3 groups were similar regarding

Guillaume Roquin

Department of Hepatogastroenterology and Digestive Oncology

CHU Angers, 4 rue Larrey

FR-49933 Angers Cedex 9 (France)

E-Mail dr.roquin@gmail.com 
age, functioning tumours, grade, the number of metastatic sites, and surgery for primary tumours, but not regarding surgery for metastases and time since diagnosis. Grade 3 NET (HR 2.15, 95\% Cl: 1.18-3.92, $p=0.012$ ) and age above 55 years (HR 1.84, 95\% Cl: 1.06-3.18, $p=0.030$ ) were associated with shorter median PFS in the multivariate analyses. Compared to streptozocin-based chemotherapy, no difference was found in terms of PFS for the platinum-based or for the dacarbazine/temozolomide-based chemotherapy regimen: median PFS was 7.2, 7.5, and 7.2 months, respectively ( $p=$ $0.51)$. Conclusions: Patients with intermediate or highly proliferative well-differentiated pNETs may benefit from 1 of the 3 chemotherapy regimens. Increased age and grade 3 were associated with shorter median PFS. Randomised studies searching for response predictors and the best efficacy-tolerance ratio are required to personalise the strategy.

(c) 2017 S. Karger AG, Basel

\section{Introduction}

Neuroendocrine neoplasms (NENs) are rare neoplasms, with an annual incidence of 5 per 100,000 [1,2]. NENs are classified as poorly differentiated neuroendocrine carcinomas (NECs) or well-differentiated neuroendocrine tumours (NETs) based on their morphology and proliferative index, which form the basis for the WHO 2010 classification [3]. Patients with NEC have a poorer prognosis than those with NET $[1,4-7]$. As part of NETs, the annual incidence of pancreatic NETs (pNETs) is estimated to be $0.30-0.60$ per $100,000[1,7$, 8 , and up to $60-80 \%$ of patients present with distant metastases or locally advanced tumours [1, 5, 9-12]. However, the outcomes of these patients are very heterogeneous. Indeed, 5-year overall survival (OS) rates of more than $75 \%$ or less than $30 \%$ have been reported for stage IV patients [9-11, 13-16]; grade and tumour burden are considered to be the 2 most important prognostic factors for substratifying these patients' prognostic outcomes $[5$, $9,10,12]$.

In advanced pNETs, multiple lines of treatment are now approved, including lanreotide-, everolimus-, sunitinib-, and streptozocin-(STZ) based chemotherapy [1720]. Current guidelines recommend STZ-based chemotherapy for aggressive pNETs as defined by a high grade (G2, Ki-67 index $>10 \%$ ), a high tumour burden, and progressive and/or symptomatic disease. In contrast, European guidelines use this cut-off of $10 \%$ (G1 or low G2) to determine whether a patient is eligible for curative surgery, for hepatic transplantation, and/or for somatostatin

Chemotherapy in Highly Proliferative pNETs analogue therapy [21-25]. In addition, alternatives to STZ-based chemotherapy are also cited, including temozolomide- or platinum-based chemotherapy regimens $[22,26]$. Indeed, renewed interest in the capecitabinetemozolomide regimen has emerged as a potential competitor of historical STZ-based chemotherapy [27]. Moreover, platinum-based chemotherapy - such as cisplatinand oxaliplatin-based chemotherapy regimens, which are currently recommended mainly for patients with poorly differentiated NECs [28] - has been reported to evoke partial responses in pNET patients including subgroups of patients with a high proliferative index [29-32]. Taken together, these results warrant clarification regarding the putative role of each of these regimens in a precisely defined aggressive pNET population of patients, and also identification of response predictors. Indeed, the Ki-67 proliferative index has been recognised as a major prognostic parameter, even if its role as putative response predictor has yet to be confirmed [33].

The aim of this study was to evaluate the antitumour efficacy of STZ-based, platinum-based, and dacarbazine/ temozolomide-based chemotherapy regimens as firstline chemotherapy for patients with aggressive advanced pNETs as defined by a Ki-67 index $\geq 10 \%$, with progression-free survival (PFS) as the primary endpoint. A retrospective multicentre study was designed within the French Group of Endocrine Tumours (GTE) to answer this question.

\section{Subjects and Methods}

\section{Patients}

All the consecutive patients who received first-line cytotoxic chemotherapy for advanced pNET in one of the centres of the GTE between 2000 and 2012 were considered for inclusion. The patients were retrospectively identified from a national registry or from hospital charts. The inclusion criteria were: (1) locally advanced or metastatic unresectable pNET; (2) a reviewed diagnosis of well-differentiated morphology as confirmed by the French pathological network (TENpath); (3) a Ki-67 index $\geq 10 \%$; (4) firstline STZ-based, platinum-etoposide-based, or dacarbazine/temozolomide-based cytotoxic chemotherapy; and (5) sporadic cases. The exclusion criteria were: (1) non-chemotherapy first-line treatment, including targeted therapy or hepatic artery embolisation; (2) absence of RECIST 1.0 [34]-evaluable imaging; and (3) presence of an inherited syndrome. Patients treated with somatostatin analogues prior to or during first-line chemotherapy were eligible. To ensure consistency, determination of eligibility and data collection were undertaken by a single investigator (G.R.) on site, with the main focus on the quality control of pathological reporting, thereby ensuring that well-conducted morphological differentiations were clearly notified and also that RECIST evaluations were adequately performed. 
The following parameters were recorded from all patients at the time of chemotherapy initiation: gender, age, main presenting symptoms (including the presence of a functioning syndrome), Ki-67 index, tumour grade, stage and number of metastatic sites, and presence of hepatic or extrahepatic metastases. All treatments received before, during, and after the first-line cytotoxic chemotherapy were recorded. The date of death or last follow-up was also recorded.

The pathological characteristics of each tumour were evaluated in one of the expert centres participating in the TENpath network [35]. The differentiation was systematically described by the pathologist of each expert centre. The Ki-67 proliferative index is expressed as a percentage based on the count of Ki-67-positive cells in 500-2,000 tumour cells in areas with the highest immunostaining using the MIB1 antibody. Grading was performed on the primary tumour in 18 cases $(25 \%)$, on the metastasis in 32 cases (44\%), or in both in 23 cases (31\%) (in the case of the last, the highest Ki-67 index was used in this study). All the pathological criteria were verified for each included patient at the time of the review of all files on site by the same investigator (G.R.). The Ki-67 index results were subclassified into 2 subgroups: $\leq 20 \%$ (grade 2 ) or $>20 \%$ (grade 3 ) according to the 2010 WHO classification as well as recent proposals [36-38].

\section{First-Line Cytotoxic Chemotherapy}

The treatment for each patient was chosen by local multidisciplinary committees of the GTE according to treatment guidelines and patient status. The following information was collected on each patient: the type of chemotherapy regimen, the total duration of first-line chemotherapy, and the dose. First-line chemotherapy was substratified into 3 subgroups: STZ-based chemotherapy (STZ-BC group), platinum-based chemotherapy (P-BC group), and dacarbazine- or temozolomide-based chemotherapy (D/T-BC group). Dosage was classified as follows: (1) full dose, if the patient received the whole dose as planned during the full course of firstline treatment, or (2) reduced dose.

Tumour Response Evaluation of First-Line Chemotherapy

Imaging follow-up was performed every 2 or 3 months with thoracic and abdominal CT scans and/or abdominal MRI. Response to chemotherapy was classified into complete response, partial response, stable disease, or progressive disease according to the RECIST 1.0 [34] criteria based on local radiological reviews. Complete and partial responses were jointly considered as objective responses (ORs). The date of progression was also recorded.

\section{Endpoints}

The primary endpoint was PFS, calculated from the date of the first-line cytotoxic chemotherapy to the date of progression or of death from any cause. Progression-free survivors at the date of last follow-up were censored. Patients receiving another treatment prior to progression (such as surgery or hepatic artery embolisation) were also censored at the time of the last evaluation before starting the second treatment. The secondary endpoint was the first-line chemotherapy response rate.

\section{Statistical Analysis}

The main patient characteristics were assessed for the whole cohort and then compared between the 3 chemotherapy-defined groups. Median OS, calculated from the onset of first-line chemo-

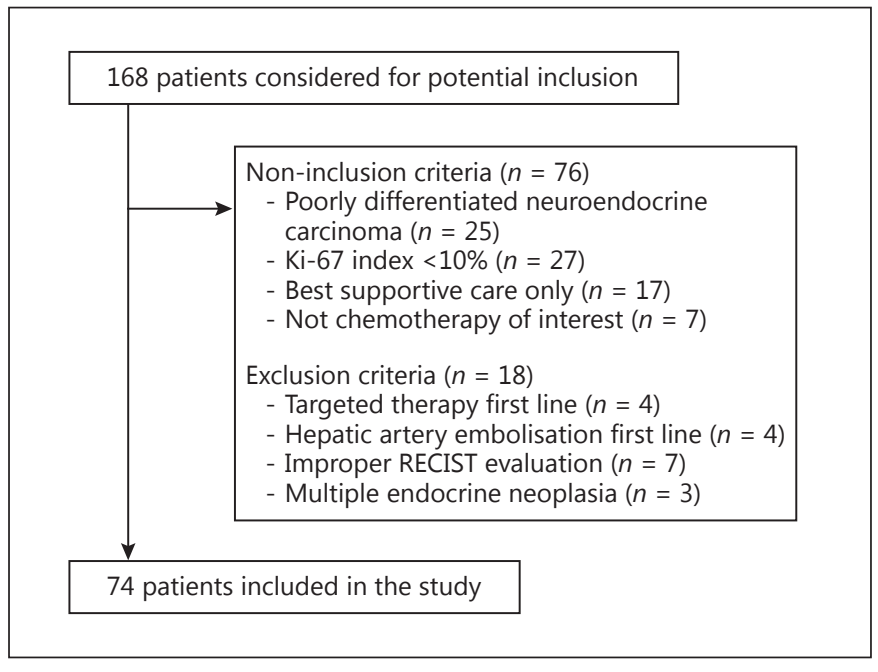

Fig. 1. Flow chart of the patients included.

therapy until death of any cause, was described and the main prognostic factors for OS were searched in our population.

Median PFS and response rates were evaluated for the whole cohort and then compared between the 3 chemotherapy-defined groups. Finally, PFS was assessed according to the chemotherapy regimen, adjusted for the main potential prognostic factors, as identified in our population and from the literature.

Qualitative variables are presented as numbers (percentages); they were compared between groups using the Fisher exact test due to the small sample size. Quantitative variables are presented as medians [ranges] and compared with the Mann-Whitney-Wilcoxon or the Kruskal-Wallis test according to the number of groups compared. PFS and OS and their 95\% CIs were estimated using the Kaplan-Meier method and compared between groups using logrank tests. Cox regression was used in our multivariate survival analyses. All statistical analyses were performed using R software version 3.1.1.

\section{Results}

\section{Patient Characteristics}

Ten centres participated in the study, and 168 files were initially considered. The following exclusion criteria were met: poorly differentiated NEC $(n=25)$; pNET with a Ki-67 index $<10 \%(n=27)$; receiving only supportive care due to deterioration in global health status $(n=17)$; and receiving chemotherapy different from the 3 regimens under investigation $(n=7)$. Furthermore, 18 patients met other exclusion criteria, as detailed in Figure 1. Finally, the 74 remaining patients were included in this study (Fig. 1).
Roquin et al. 
Table 1. Characteristics of the study population according to the regimen received as first-line chemotherapy

\begin{tabular}{|c|c|c|c|c|c|}
\hline Characteristics & $\begin{array}{l}\text { All patients } \\
(n=74)\end{array}$ & $\begin{array}{l}\text { STZ-BC group } \\
(n=44)\end{array}$ & $\begin{array}{l}\text { P-BC group } \\
(n=18)\end{array}$ & $\begin{array}{l}\text { D/T-BC group } \\
(n=12)\end{array}$ & $p$ value \\
\hline Male gender & $42(57 \%)$ & $27(61 \%)$ & $6(33 \%)$ & $9(75 \%)$ & 0.055 \\
\hline Age, years & $55.5[33.6-78.7]$ & $55.4[35.3-77.0]$ & $55.1[33.6-78.7]$ & $59.9[37.0-75.3]$ & $0.73^{\mathrm{a}}$ \\
\hline \multicolumn{6}{|c|}{ Main presenting symptom ( $n=71$ eligible for analysis) } \\
\hline Functioning tumours & $7(10 \%)$ & $5(11 \%)$ & $1(6 \%)$ & $1(8 \%)$ & \multirow[t]{8}{*}{0.68} \\
\hline Abdominal pain & $20(28 \%)$ & $11(25 \%)$ & $8(44 \%)$ & $1(8 \%)$ & \\
\hline Tumour mass & $18(25 \%)$ & $12(27 \%)$ & $3(17 \%)$ & $3(25 \%)$ & \\
\hline Incidental finding & $10(14 \%)$ & $6(14 \%)$ & $2(11 \%)$ & $2(17 \%)$ & \\
\hline Jaundice & $5(7 \%)$ & $3(7 \%)$ & $0(0 \%)$ & $2(17 \%)$ & \\
\hline Asthenia/weight loss & $4(6 \%)$ & $2(5 \%)$ & $1(6 \%)$ & $1(8 \%)$ & \\
\hline Diarrhoea & $3(4 \%)$ & $1(2 \%)$ & $1(6 \%)$ & $1(8 \%)$ & \\
\hline Other & $4(6 \%)$ & $3(7 \%)$ & $1(6 \%)$ & $0(0 \%)$ & \\
\hline Ki-67 index & $18[10-60]$ & $15[10-60]$ & $20[10-50]$ & $18[10-42]$ & $0.31^{\mathrm{a}}$ \\
\hline Grade 3 tumours & $23(31 \%)$ & $10(23 \%)$ & $8(44 \%)$ & $5(42 \%)$ & 0.16 \\
\hline \multicolumn{6}{|l|}{ Stage (number of $M+$ sites) } \\
\hline III & $13(18 \%)$ & $5(11 \%)$ & $4(22 \%)$ & $4(33 \%)$ & \multirow[t]{3}{*}{0.41} \\
\hline IV (1 M+ site) & $30(40 \%)$ & $18(41 \%)$ & $8(44 \%)$ & $4(33 \%)$ & \\
\hline IV ( $\geq 2 \mathrm{M}+$ sites $)$ & $31(42 \%)$ & $21(48 \%)$ & $6(33 \%)$ & $4(33 \%)$ & \\
\hline Hepatic metastases & $60(81 \%)$ & $39(89 \%)$ & $13(72 \%)$ & $8(67 \%)$ & 0.11 \\
\hline Extra-hepatic metastases & $31(42 \%)$ & $21(48 \%)$ & $6(33 \%)$ & $4(33 \%)$ & 0.54 \\
\hline \multicolumn{6}{|c|}{ Treatment prior to first-line chemotherapy } \\
\hline Primary tumour surgery & $28(38 \%)$ & $15(34 \%)$ & $5(28 \%)$ & $8(67 \%)$ & 0.088 \\
\hline Metastatic surgery & $14(19 \%)$ & $9(20 \%)$ & $0(0 \%)$ & $5(42 \%)$ & 0.0071 \\
\hline Somatostatin analogue & $9(12 \%)$ & $6(14 \%)$ & $1(6 \%)$ & $2(17 \%)$ & 0.69 \\
\hline Radiotherapy & $4(5 \%)$ & $1(2 \%)$ & $1(6 \%)$ & $2(17 \%)$ & 0.11 \\
\hline Time since diagnosis, months & $3.8[0.1-73.6]$ & $5.3[0.1-44.1]$ & $1.6[0.4-73.6]$ & $13.5[0.1-72.1]$ & $<0.001^{\mathrm{a}}$ \\
\hline Duration of chemotherapy, months & $4.8[1.4-29.4]$ & $5.5[1.4-29.4]$ & $4.4[2.3-17.4]$ & $4.4[2.1-15.9]$ & $0.63^{\mathrm{a}}$ \\
\hline Follow-up duration, months & $25.6[1.0-136.0]$ & $28.1[1.0-136.0]$ & $25.7[2.3-88.4]$ & $19.8[3.7-53.1]$ & $0.60^{\mathrm{a}}$ \\
\hline OS, ${ }^{\mathrm{c}}$ months & $36.3(25.2-50.0)$ & $37.9(20.8-\mathrm{NE})$ & $27.1(20.9-\mathrm{NE})$ & $40.9(17.1-\mathrm{NE})$ & $0.94^{\mathrm{b}}$ \\
\hline
\end{tabular}

Values are presented as $n(\%)$ or median [range] unless specified otherwise. $p$ value: Fisher exact tests, otherwise specified. NE, not evaluable; $\mathrm{M}+$ site, metastatic site; STZ-BC, streptozocin-based chemotherapy; P-BC, platinum-based chemotherapy; D/T-BC, dacarbazine/temozolomide-based chemotherapy; OS, overall survival. ${ }^{a}$ Kruskal-Wallis tests. ${ }^{\mathrm{b}}$ log-rank test. ${ }^{\mathrm{c}} \mathrm{Median}(95 \% \mathrm{CI})$.

There were 42 men (57\%) and the median age of the population was 55.5 years (range: 33.6-78.7) (Table 1). The main presenting symptom was abdominal pain in 20 patients (28\%). Seven patients (10\%) had functioning tumours, including 3 gastrinomas. Sixty-one patients (82\%) were stage IV, including 31 (42\%) with 2 or more metastatic sites. Sixty patients $(81 \%)$ had liver metastases. The median value of the Ki-67 index was 18 (range: 10-60), including 51 patients (69\%) classified as grade 2 and 23 $(31 \%)$ as grade 3 . Surgery of the primary tumour before first-line chemotherapy was performed in 28 patients $(38 \%)$ and metastatic surgery in $14(19 \%)$. Nine patients (12\%) received somatostatin analogues and $4(5 \%)$ were treated with radiotherapy before first-line chemotherapy. No difference in any of these characteristics was found between grade 2 and grade 3 patients (data not shown).

Chemotherapy in Highly Proliferative pNETs

\section{Overall Survival}

The median duration of follow-up (started at the onset of first-line chemotherapy) was 25.6 months (1.0-136.0), without any difference according to the first-line chemotherapy regimen received (Table 1). Forty-five deaths were recorded during the study.

The median OS for the whole cohort was 36.3 months (25.2-50.0), with 1-, 3-, and 5-year survival rates of $83 \%$ (75-92), 50\% (39-64), and 29\% (18-46), respectively. In the multivariate analysis, only surgery of the primary tumours was found to be positively associated with OS $(\mathrm{HR}=0.38,95 \% \mathrm{CI}: 0.19-0.78, p=0.008)$. A non-significant trend for poorer prognosis was found for patients with grade 3 tumours (HR $=1.81,95 \%$ CI: $0.90-3.63, p=$ $0.095)$. The median OS was 50.0 months (33.4-not evaluable [NE]) for patients undergoing primary tumour sur-

Neuroendocrinology 2018;106:38-46 DOI: $10.1159 / 000457955$ 


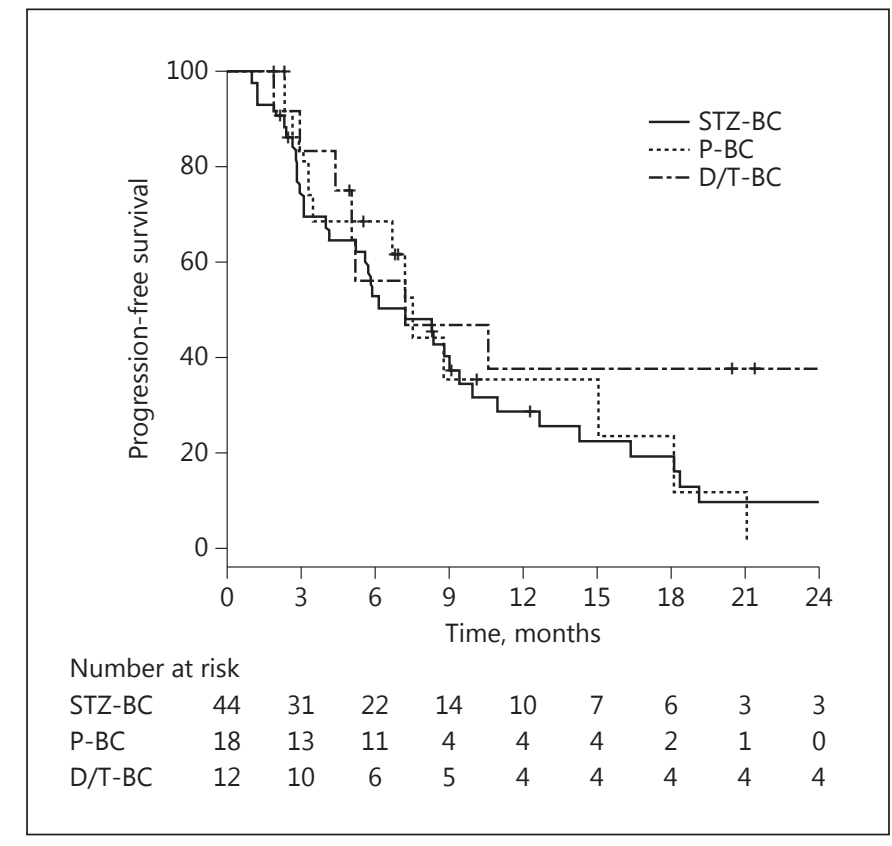

Fig. 2. Progression-free survival according to the first-line chemotherapy regimen $(n=74)$. Test $\log$-rank $p=0.51$. STZ-BC, streptozocin-based chemotherapy; P-BC, platinum-based chemotherapy; D/T-BC, dacarbazine/temozolomide-based chemotherapy.

gery, and 27.1 months (19.1-42.8) for patients without primary tumour surgery $(p=0.023)$. The median OS was 37.9 months (26.0-71.3) for patients with grade 2 tumours, and 20.9 months (17.1-NE) for patients with grade 3 tumours $(p=0.54)$.

\section{First-Line Chemotherapy}

Regarding the chemotherapy regimen, 44 patients received STZ-BC (including STZ + doxorubicin $[n=33]$, $\mathrm{STZ}+5$-fluorouracil [5-FU] $[n=8], \mathrm{STZ}+5-\mathrm{FU}+$ bevacizumab $[n=2]$, and STZ + epirubicin $[n=1]), 18$ patients received P-BC (including cisplatin + etoposide $[n=$ 16] and carboplatin + etoposide $[n=2])$, and 12 patients received $\mathrm{D} / \mathrm{T}-\mathrm{BC}$ (including temozolomide alone $[n=2]$, temozolomide + capecitabine $[n=4]$, dacarbazine +5 -FU $[n=2]$, and dacarbazine $+5-\mathrm{FU}+$ epirubicin $[n=4])$. The median delay between the diagnosis of metastasis and the onset of first-line chemotherapy was 3.8 months (0.173.6).

There was no difference between the 3 groups in terms of age, grading of the tumour, the number of metastatic sites at diagnosis, and primary tumour surgery (Table 1). Metastatic surgery prior to first-line chemotherapy was more frequent in the D/T-BC group (42\%, 5 patients) than in the STZ-BC group (20\%, 9 patients) and in the P-BC group (no patient) $(p=0.0071)$. In addition, the median length of time from diagnosis of metastasis was 5.3 months (0.1-44.1), 1.6 months (0.4-73.6), and 13.5 months $(0.1-72.1)$ for the STZ-BC, the P-BC, and the $\mathrm{D} / \mathrm{T}-\mathrm{BC}$ group, respectively $(p<0.001)$ (Table 1$)$.

The median duration of first-line chemotherapy was 4.8 months (1.4-29.4), with no differences between the 3 groups. Forty-nine patients received full-dose chemotherapy, while 14 received reduced-dose chemotherapy, without any difference between the groups (missing data for 11 patients).

\section{PFS and Rates of Response to First-Line Chemotherapy}

The median PFS was 7.2 months (5.7-9.9) for the whole population. In univariate analysis, there was no difference in median PFS according to the type of first-line chemotherapy regimen: 7.2 months (95\% CI: 5.2-11.0), 7.5 months (95\% CI: 3.5-NE), and 7.2 months (95\% CI: $5.0-\mathrm{NE}$ ) in the STZ-BC group, the $\mathrm{P}-\mathrm{BC}$ group, and the $\mathrm{D} / \mathrm{T}-\mathrm{BC}$ group, respectively $(p=0.51$ ) (Fig. 2 ).

In multivariate Cox regression analysis, grade $3(\mathrm{HR}=$ $2.15,95 \%$ CI: $1.18-3.92, p=0.012)$ and age over 55 years $(\mathrm{HR}=1.84$, 95\% CI: $1.06-3.18, p=0.030)$ were significantly and independently associated with shorter PFS, but there was only a non-significant trend for a better median PFS for the D/T-BC group compared to the STZBC group (HR $=0.52,95 \%$ CI: $0.24-1.13, p=0.099)(\mathrm{Ta}-$ ble 2). Median PFS was longer in patients with grade 2 tumours (8.8 months, 95\% CI: 6.7-15.0) than in those with grade 3 tumours (5.6 months, 95\% CI: $3.5-10.5, p=$ $0.074)$. Primary tumour surgery was not associated with PFS. When STZ-BC and D/T-BC were grouped together and compared to $\mathrm{P}-\mathrm{BC}$, no significant difference was observed regarding PFS (data not shown).

According to the RECIST, an OR after first-line chemotherapy was observed in 21 patients (29\%); 25 (34\%) had stable disease and 27 (37\%) had progressive disease. The response rates did not differ significantly between the 3 groups (Table 3). Again, no difference was observed with regard to grade (data not shown).

\section{Treatments Received following First-Line Chemotherapy}

The median of the total number of treatment lines (either chemotherapy or biotherapy) was 2 (1-9), with no difference regarding the first-line chemotherapy regimen $(p=0.28)$. Fifty-eight patients $(78 \%)$ received a second line of treatment: 5 received STZ-BC, 10 P-BC, 13 D/T-
Roquin et al. 
Table 2. Progression-free survival (Cox regression analysis) $(n=74)$

\begin{tabular}{|c|c|c|c|c|c|}
\hline \multirow[t]{2}{*}{ Risk factors } & \multirow[t]{2}{*}{ Patients, $n(\%)$} & \multicolumn{2}{|l|}{ Univariate analysis } & \multicolumn{2}{|c|}{ Multivariate analysis } \\
\hline & & HR (95\% CI) & $p$ & HR (95\% CI) & $p$ \\
\hline \multicolumn{6}{|l|}{ Chemotherapy regimen } \\
\hline STZ-BC & $44(59 \%)$ & 1.00 & & 1.00 & \\
\hline P-BC & $18(24 \%)$ & $0.96(0.50-1.86)$ & 0.90 & $0.89(0.46-1.74)$ & 0.73 \\
\hline $\mathrm{D} / \mathrm{T}-\mathrm{BC}$ & $12(16 \%)$ & $0.65(0.31-1.36)$ & 0.26 & $0.52(0.24-1.13)$ & 0.099 \\
\hline Age $>55$ years & $40(54 \%)$ & $1.48(0.87-2.50)$ & 0.15 & $1.84(1.06-3.18)$ & 0.030 \\
\hline Grade 3 tumours & $23(31 \%)$ & $1.67(0.95-2.95)$ & 0.076 & $2.15(1.18-3.92)$ & 0.012 \\
\hline Stage IV & $61(82 \%)$ & $1.31(0.64-2.69)$ & 0.46 & $1.71(0.80-3.64)$ & 0.16 \\
\hline Surgery of primary tumour & $28(38 \%)$ & $0.90(0.52-1.54)$ & 0.69 & - & - \\
\hline Metastatic surgery & $14(19 \%)$ & $0.80(0.40-1.59)$ & 0.53 & - & - \\
\hline
\end{tabular}

Factors with an HR $>1$ are associated with decreased progression-free survival. STZ-BC, streptozocin-based chemotherapy; P-BC, platinum-based chemotherapy; D/T-BC, dacarbazine/temozolomide-based chemotherapy.

Table 3. PFS and response rates by first-line chemotherapy regimen $(n=74)$

\begin{tabular}{llccc}
\hline & STZ-BC $(n=44)$ & P-BC $(n=18)$ & D/T-BC $(n=12)$ & $p$ value \\
\hline Median PFS in months (95\% CI) & $7.2(5.2-11.0)$ & $7.5(3.5-\mathrm{NE})$ & $7.2(5.0-\mathrm{NE})$ & 0.51 \\
Response rate $(n=73$ eligible for analysis) & & & & \\
$\quad$ & $11(26 \%)$ & $4(22 \%)$ & $6(50 \%)$ & 0.37 \\
$\quad$ Objective response & $13(30 \%)$ & $10(56 \%)$ & $2(17 \%)$ & \\
$\quad$ Stable disease & $19(44 \%)$ & $4(22 \%)$ & $4(33 \%)$ \\
$\quad$ Disease progression &
\end{tabular}

p values: log-rank test (median PFS); Kruskal-Wallis test (response rate). STZ-BC, streptozocin-based chemotherapy; P-BC, platinum-based chemotherapy; D/T-BC, dacarbazine/temozolomide-based chemotherapy; PFS, progression-free survival.

$\mathrm{BC}$, and 15 another regimen of chemotherapy; 15 were treated with targeted therapies. Finally, 36 patients received 3 or more lines of treatment.

\section{Discussion}

In a population of intermediate to highly proliferative and advanced pNET patients with Ki-67 indices $>10 \%$, our study underlines 2 important results: (1) STZ-BC was the first-line regimen most frequently used by French investigators, but $\mathrm{P}-\mathrm{BC}$ was still used in $24 \%$ of the cases, demonstrating an absence of consensus between local physicians, and (2) an age $>55$ years and grade 3 NET were significantly and independently associated with shorter PFS, whereas the chemotherapy regimen used (STZ-BC, P-BC, and D/T-BC) did not influence PFS which challenges the current ENETS or NCCN guidelines $[22,39]$. The cut-off of a Ki-67 index $\geq 10 \%$ was chosen to select intermediate to highly proliferative pNETs based on recent ENETS guidelines [21-25], prognostic influence as demonstrated in surgical series, and also its association with higher uptake of fluorodeoxyglucose.

In our study, focusing on intermediate or highly proliferative pNETs, the median OS was shorter ( 36.3 months) than in previous studies on stage IV pNETs [5, $9,11,12,16]$. In line with this, other features also highlight the aggressiveness of the disease in our population: functioning tumours were rare $(10 \%), 31 \%$ of the patients were classified as grade 3 , and only $38 \%$ of the patients had previously undergone primary tumour surgery. Median OS is mainly influenced by primary tumour surgery, as previously reported [14, 40-42].

In the absence of known response predictors, and head-to-head comparisons of medical options for pNET patients, there is a lack of consensus regarding the best first-line therapy for pNET. According to current guidelines, chemotherapy is recommended for patients with 
aggressive pNET, and the type of regimen is based on the differentiation status, which refers to both the morphology and the proliferative index. Historically, STZ-BC has been considered the standard treatment for aggressive pNET, and P-BC for the treatment of pNEC. In how far the Ki-67 proliferative index alone contributes to the antitumour impact of these regimens is open to debate [30, 36, 43-46]. Recently, the use of P-BC for aggressive NET was re-challenged, and $\mathrm{D} / \mathrm{T}-\mathrm{BC}$ was proposed as an alternative strategy to the historical STZ-BC regimen $[27,47$, 48]. A few studies have specifically addressed the role of $\mathrm{P}-\mathrm{BC}$ in patients classified into the newly described grade 3 NET category, which represents $31 \%$ of the population of our study. Although a lower rate of response to P-BC was found for grade 3 NET compared to NEC, some degree of tumour response was reported, ranging from 0 to $17 \%[29,36,38]$. In addition, Sorbye et al. [31] reported an $11 \%$ partial response rate with $\mathrm{P}-\mathrm{BC}$ in patients with NENs defined by a Ki-67 index $<55 \%$.

A median PFS of 7.2 months and an OR rate of $29 \%$ were found in our study regardless of the cytotoxic regimen used, calling for prospective studies and translational research to rationalise the best strategy for any given patient. Indeed, we were unable to demonstrate that alkylating agents (STZ-BC and D/T-BC combined) were associated with longer PFS when compared to a P-BC regimen. Meanwhile, a cytotoxic regimen with alkylating agents, since associated with better tolerance, may be favoured [49-52]. Walter et al. [51] recently confirmed that $\mathrm{O}^{6}$-methylguanine-DNA methyltransferase status was associated with higher response rates to alkylating agentbased chemotherapy. Such a molecular marker, if prospectively confirmed, could be the first step towards a kind of individualised strategy.

Efforts were made to perform an in-depth evaluation of the heterogeneity of the population characteristics studied. Although no major differences in key prognostic parameters were observed across the 3 groups of patients, the number of metastatic surgeries as well as the length of time from diagnosis to chemotherapy initiation were found to be significantly different (i.e., less frequent and shorter) in the $\mathrm{P}-\mathrm{BC}$ subgroup. In addition, a non-significant trend towards more aggressive prognostic features, such as a higher percentage of grade 3 tumours and a lower frequency of primary tumour surgery, was also observed among pNET patients who received P-BC. Overall, the selection of patients with a high Ki-67 index may have optimised the P-BC but not the STZ-BC or D/T-BC results and converged into comparable results from these different lines of chemotherapy in this patient population
[46]. Indeed, both median PFS and OR rates among pNET patients who received STZ-BC or D/T-BC were found to be in the low range of results provided by previous studies [17, 27, 46, 51, 53-56]. In line with this comment is the remark that the fact that patients with grade 3 pNET experienced a shorter median PFS than those with grade 2 pNET also shows that Ki-67 alone is not a good predictor of chemotherapy.

Our results should be interpreted with caution, due to the multicentre and retrospective design of our study as well as the heterogeneity of the population and the regimen used. In addition, safety was not evaluated. However, this study is, to our knowledge, the first to attempt an analysis of the results of various first-line chemotherapy regimens in a population of intermediate or highly proliferative pNET patients with reviewed morphology for differentiation.

In conclusion, patients with intermediate or highly proliferative well-differentiated pNETs may benefit from 1 of the 3 chemotherapy regimens. Increased age and grade 3 tumours were associated with shorter median PFS. Randomised studies searching for response predictors and the best efficacy-tolerance ratio are required to personalise treatment strategies.

\section{Acknowledgements}

We wish to thank Nathanaëlle Cornet for collecting and assembling the data. This research did not receive any specific grant from any funding agency in the public, commercial, or not-for-profit sector.

\section{Author Contributions}

Conception and design: all authors; collection of data: all authors; assembly and analysis of data: G.R. and A.R.-R.; data interpretation: G.R., E.B., F.-X.C.-B., G.C., T.W., O.H., and V.R.; manuscript writing: G.R., E.B., F.-X.C.-B., G.C., T.W., O.H., C.L.-B., and A.R.-R.; final approval of the manuscript: all authors.

References

1 Yao JC, Hassan M, Phan A, Dagohoy C, Leary C, Mares JE, et al: One hundred years after "carcinoid": epidemiology of and prognostic factors for neuroendocrine tumors in 35,825 cases in the United States. J Clin Oncol 2008; 26:3063-3072.

2 Lepage C, Bouvier AM, Faivre J: Endocrine tumours: epidemiology of malignant digestive neuroendocrine tumours. Eur J Endocrinol 2013;168:R77-R83.
44

Neuroendocrinology 2018;106:38-46 DOI: $10.1159 / 000457955$
Roquin et al. 
3 Bosman FT; World Health Organization, International Agency for Research on Cancer (eds): WHO classification of tumours of the digestive system, ed 4. Lyon, International Agency for Research on Cancer, 2010.

4 Madeira I, Terris B, Voss M, Denys A, Sauvanet A, Flejou J-F, et al: Prognostic factors in patients with endocrine tumours of the duodenopancreatic area. Gut 1998;43:422-427.

5 Panzuto F, Boninsegna L, Fazio N, Campana D, Pia Brizzi M, Capurso G, et al: Metastatic and locally advanced pancreatic endocrine carcinomas: analysis of factors associated with disease progression. J Clin Oncol 2011; 29:2372-2377.

6 Baudin E, Planchard D, Scoazec J-Y, Guigay J, Dromain C, Hadoux J, et al: Intervention in gastro-enteropancreatic neuroendocrine tumours. Best Pract Res Clin Gastroenterol 2012;26:855-865.

7 Korse CM, Taal BG, van Velthuysen M-LF, Visser O: Incidence and survival of neuroendocrine tumours in the Netherlands according to histological grade: experience of two decades of cancer registry. Eur J Cancer 2013; 49:1975-1983.

8 Hallet J, Law CHL, Cukier M, Saskin R, Liu N, Singh S: Exploring the rising incidence of neuroendocrine tumors: a population-based analysis of epidemiology, metastatic presentation, and outcomes. Cancer 2015;121:589597.

9 Ekeblad S, Skogseid B, Dunder K, Öberg K, Eriksson B: Prognostic factors and survival in 324 patients with pancreatic endocrine tumor treated at a single institution. Clin Cancer Res 2008; 14:7798-7803.

10 Pape U-F, Berndt U, Müller-Nordhorn J, Böhmig M, Roll S, Koch M, et al: Prognostic factors of long-term outcome in gastroenteropancreatic neuroendocrine tumours. Endocr Relat Cancer 2008;15:1083-1097.

11 Scarpa A, Mantovani W, Capelli P, Beghelli S, Boninsegna L, Bettini R, et al: Pancreatic endocrine tumors: improved TNM staging and histopathological grading permit a clinically efficient prognostic stratification of patients. Mod Pathol 2010;23:824-833.

12 Strosberg JR, Cheema A, Weber J, Han G, Coppola D, Kvols LK: Prognostic validity of a novel American Joint Committee on Cancer Staging Classification for pancreatic neuroendocrine tumors. J Clin Oncol 2011;29:30443049.

13 Metz DC, Jensen RT: Gastrointestinal neuroendocrine tumors: pancreatic endocrine tumors. Gastroenterology 2008;135:1469-1492.

14 Durante C, Boukheris H, Dromain C, Duvillard P, Leboulleux S, Elias D, et al: Prognostic factors influencing survival from metastatic (stage IV) gastroenteropancreatic well-differentiated endocrine carcinoma. Endocr Relat Cancer 2009;16:585-597.

15 Strosberg J, Gardner N, Kvols L: Survival and prognostic factor analysis of 146 metastatic neuroendocrine tumors of the mid-gut. Neuroendocrinology 2009;89:471-476.
16 Fischer L, Bergmann F, Schimmack S, Hinz U, Priess S, Müller-Stich BP, et al: Outcome of surgery for pancreatic neuroendocrine neoplasms. Br J Surg 2014;101:1405-1412.

17 Moertel CG, Lefkopoulo M, Lipsitz S, Hahn RG, Klaassen D: Streptozocin-doxorubicin, streptozocin-fluorouracil or chlorozotocin in the treatment of advanced islet-cell carcinoma. N Engl J Med 1992;326:519-523.

18 Raymond E, Dahan L, Raoul J-L, Bang Y-J, Borbath I, Lombard-Bohas C, et al: Sunitinib malate for the treatment of pancreatic neuroendocrine tumors. N Engl J Med 2011;364: 501-513.

19 Yao JC, Shah MH, Ito T, Bohas CL, Wolin EM, Van Cutsem E, et al: Everolimus for advanced pancreatic neuroendocrine tumors. N Engl J Med 2011;364:514-523.

20 Caplin ME, Pavel M, Ćwikła JB, Phan AT, Raderer M, Sedláčková E, et al: Lanreotide in metastatic enteropancreatic neuroendocrine tumors. N Engl J Med 2014;371:224-233.

21 Olausson M, Friman S, Herlenius G, Cahlin C, Nilsson O, Jansson S, et al: Orthotopic liver or multivisceral transplantation as treatment of metastatic neuroendocrine tumors. Liver Transpl 2007;13:327-333.

22 Pavel M, O'Toole D, Costa F, Capdevila J, Gross D, Kianmanesh R, et al: ENETS Consensus Guidelines update for the management of distant metastatic disease of intestinal, pancreatic, bronchial neuroendocrine neoplasms (NEN) and NEN of unknown primary site. Neuroendocrinology 2016;103: 172-185.

23 Cadiot G, Adham M, Baudin E, Couvelard A, Lombard-Bohas C, Mitry E, et al: Thésaurus National de Cancérologie Digestive: Tumeurs neuroendocrines digestives |SNFGE.org Société savante médicale française d'hépatogastroentérologie et d'oncologie digestive 2014. http://www.snfge.org/content/11-tumeurs-neuroendocrines-digestives\#ref5011.

24 Le Treut YP, Grégoire E, Belghiti J, Boillot O, Soubrane O, Mantion G, et al: Predictors of long-term survival after liver transplantation for metastatic endocrine tumors: an 85-case French multicentric report. Am J Transplant 2008;8:1205-1213.

25 Caplin ME, Pavel M, Ćwikła JB, Phan AT, Raderer M, Sedláčková E, et al: Lanreotide in metastatic enteropancreatic neuroendocrine tumors. N Engl J Med 2014;371:224-233.

26 Kunz PL, Reidy-Lagunes D, Anthony LB, Bertino EM, Brendtro K, Chan JA, et al: Consensus guidelines for the management and treatment of neuroendocrine tumors. Pancreas 2013;42:557-577.

27 Strosberg JR, Fine RL, Choi J, Nasir A, Coppola D, Chen D-T, et al: First-line chemotherapy with capecitabine and temozolomide in patients with metastatic pancreatic endocrine carcinomas. Cancer 2011;117:268-275.
28 Garcia-Carbonero R, Sorbye H, Baudin E, Raymond E, Wiedenmann B, Niederle B, et al: ENETS Consensus Guidelines for high-grade gastroenteropancreatic neuroendocrine tumors and neuroendocrine carcinomas. Neuroendocrinology 2016;103:186-194.

29 Hentic O, Couvelard A, Rebours V, Zappa M, Dokmak S, Hammel P, et al: Ki-67 index, tumor differentiation, and extent of liver involvement are independent prognostic factors in patients with liver metastases of digestive endocrine carcinomas. Endocr Relat Cancer 2010;18:51-59.

30 Turner NC, Strauss SJ, Sarker D, Gillmore R, Kirkwood A, Hackshaw A, et al: Chemotherapy with 5-fluorouracil, cisplatin and streptozocin for neuroendocrine tumours. Br J Cancer 2010;102:1106-1112.

31 Sorbye H, Welin S, Langer SW, Vestermark LW, Holt N, Osterlund P, et al: Predictive and prognostic factors for treatment and survival in 305 patients with advanced gastrointestinal neuroendocrine carcinoma (WHO G3): the NORDIC NEC study. Ann Oncol 2013;24: 152-160.

32 Dussol A-S, Joly M-O, Vercherat C, Forestier J, Hervieu V, Scoazec J-Y, et al: Gemcitabine and oxaliplatin or alkylating agents for neuroendocrine tumors: comparison of efficacy and search for predictive factors guiding treatment choice. Cancer 2015;121:3428-3434.

33 O’Toole D, Couvelard A, Rebours V, Zappa M, Hentic O, Hammel P, et al: Molecular markers associated with response to chemotherapy in gastro-entero-pancreatic neuroendocrine tumors. Endocr Relat Cancer 2010; 17:847-856

34 Therasse P, Arbuck SG, Eisenhauer EA, Wanders J, Kaplan RS, Rubinstein L, et al: New guidelines to evaluate the response to treatment in solid tumors. European Organization for Research and Treatment of Cancer, National Cancer Institute of the United States, National Cancer Institute of Canada. J Natl Cancer Inst 2000;92:205-216.

35 Scoazec J-Y: Le réseau TENpath, réseau d'expertise anatomopathologique des tumeurs neuroendocrines malignes de l'adulte, sporadiques et familiales: premier bilan et premières leçons. Ann Pathol 2014;34:34-39.

36 Vélayoudom-Céphise F-L, Duvillard P, Foucan L, Hadoux J, Chougnet CN, Leboulleux S, et al: Are G3 ENETS neuroendocrine neoplasms heterogeneous? Endocr Relat Cancer 2013;20:649-657.

37 Basturk O, Yang Z, Tang LH, Hruban RH, Adsay V, McCall CM, et al: The high-grade (WHO G3) pancreatic neuroendocrine tumor category is morphologically and biologically heterogenous and includes both well differentiated and poorly differentiated neoplasms. Am J Surg Pathol 2015;39:683-690.

38 Heetfeld M, Chougnet CN, Olsen IH, Rinke A, Borbath I, Crespo G, et al: Characteristics and treatment of patients with G3 gastroenteropancreatic neuroendocrine neoplasms. Endocr Relat Cancer 2015;22:657-664.
Chemotherapy in Highly Proliferative pNETs
Neuroendocrinology 2018;106:38-46 DOI: $10.1159 / 000457955$ 
39 Kulke MH, Shah MH, Benson AB 3rd, Bergsland E, Berlin JD, Blaszkowsky LS, et al: Neuroendocrine tumors, version 1.2015. J Natl Compr Canc Netw 2015;13:78-108.

40 Ahmed A, Turner G, King B, Jones L, Culliford D, McCance D, et al: Midgut neuroendocrine tumours with liver metastases: results of the UKINETS study. Endocr Relat Cancer 2009;16:885-894.

41 Zerbi A, Capitanio V, Boninsegna L, Delle Fave G, Pasquali C, Rindi G, et al: Treatment of malignant pancreatic neuroendocrine neoplasms: middle-term (2-year) outcomes of a prospective observational multicentre study. HPB (Oxford) 2013;15:935-943.

42 Martin-Perez E, Capdevila J, Castellano D, Jimenez-Fonseca P, Salazar R, BeguiristainGomez A, et al: Prognostic factors and longterm outcome of pancreatic neuroendocrine neoplasms: Ki-67 index shows a greater impact on survival than disease stage. The large experience of the Spanish National Tumor Registry (RGETNE). Neuroendocrinology 2013;98:156-168.

43 Vilar E, Salazar R, Pérez-García J, Cortes J, Öberg K, Tabernero J: Chemotherapy and role of the proliferation marker Ki-67 in digestive neuroendocrine tumors. Endocr Relat Cancer 2007;14:221-232.

44 Scoazec J-Y, Couvelard A, Monges G, Leteurtre E, Belleannée G, Guyetant S, et al: Welldifferentiated grade 3 digestive neuroendocrine tumors: myth or reality? The PRONET study group. J Clin Oncol 2012;30:abstract 4129 .
45 Sorbye H, Strosberg J, Baudin E, Klimstra DS, Yao JC: Gastroenteropancreatic high-grade neuroendocrine carcinoma. Cancer 2014; 120:2814-2823.

46 Dilz L-M, Denecke T, Steffen IG, Prasad V, von Weikersthal LF, Pape U-F, et al: Streptozocin/5-fluorouracil chemotherapy is associated with durable response in patients with advanced pancreatic neuroendocrine tumours. Eur J Cancer 2015;51:1253-1262.

47 Fine RL, Gulati AP, Krantz BA, Moss RA, Schreibman S, Tsushima DA, et al: Capecitabine and temozolomide (CAPTEM) for metastatic, well-differentiated neuroendocrine cancers: the Pancreas Center at Columbia University experience. Cancer Chemother Pharmacol 2013;71:663-670.

48 Abbasi S, Kashashna A, Albaba H: Efficacy of capecitabine and temozolomide combination in well-differentiated neuroendocrine tumors: Jordan experience. Pancreas 2014;43: 1303-1305.

49 Ekeblad S, Sundin A, Janson ET, Welin S, Granberg D, Kindmark H, et al: Temozolomide as monotherapy is effective in treatment of advanced malignant neuroendocrine tumors. Clin Cancer Res 2007;13:2986-2991.

50 Kulke MH, Hornick JL, Frauenhoffer C, Hooshmand S, Ryan DP, Enzinger PC, et al: $\mathrm{O}^{6}$-methylguanine DNA methyltransferase deficiency and response to temozolomidebased therapy in patients with neuroendocrine tumors. Clin Cancer Res 2009;15:338345 .
51 Walter T, van Brakel B, Vercherat C, Hervieu $\mathrm{V}$, Forestier J, Chayvialle J-A, et al: $O^{6}$-methylguanine-DNA methyltransferase status in neuroendocrine tumours: prognostic relevance and association with response to alkylating agents. Br J Cancer 2015;112:523-531.

52 Cives M, Ghayouri M, Morse B, Brelsford M, Black M, Rizzo A, et al: Analysis of potential response predictors to capecitabine/temozolomide in metastatic pancreatic neuroendocrine tumors. Endocr Relat Cancer 2016; 23:759-767.

53 Delaunoit T, Ducreux M, Boige V, Dromain C, Sabourin J-C, Duvillard P, et al: The doxorubicin-streptozotocin combination for the treatment of advanced well-differentiated pancreatic endocrine carcinoma. Eur J Cancer 2004;40:515-520.

54 Kouvaraki MA, Ajani JA, Hoff P, Wolff R, Evans DB, Lozano R, et al: Fluorouracil, doxorubicin, and streptozocin in the treatment of patients with locally advanced and metastatic pancreatic endocrine carcinomas. J Clin Oncol 2004;22:4762-4771.

55 Fjällskog M-LH, Janson ET, Falkmer UG, Vatn MH, Öberg KE, Eriksson BK: Treatment with combined streptozotocin and liposomal doxorubicin in metastatic endocrine pancreatic tumors. Neuroendocrinology 2008; 88 : 53-58.

56 Meyer T, Qian W, Caplin ME, Armstrong G, Lao-Sirieix S-H, Hardy R, et al: Capecitabine and streptozocin \pm cisplatin in advanced gastroenteropancreatic neuroendocrine tumours. Eur J Cancer 2014;50:902-911. 